\title{
Integrating Internet Video Conferencing Techniques And Online Delivery Systems With Hybrid Classes To Enhance Student Interaction And Learning In Accelerated Programs \\ E. George Beckwith, Ed.D., National University, USA \\ Daniel T. Cunniff, Ph.D., National University, USA
}

\begin{abstract}
Online course enrollment has increased dramatically over the past few years. The authors cite the reasons for this rapid growth and the opportunities open for enhancing teaching/learning techniques such as video conferencing and hybrid class combinations. The authors outlined an example of an accelerated learning, eight-class session course detailing effective instructional techniques.
\end{abstract}

Keywords: Hybrid, Accelerated Program, Online delivery, video conferencing

\section{INTRODUCTION}

$\mathscr{A}$

s online course enrollment increases across the nation in both high school and college levels - but particularly for working adults at the college level, accelerated classes could be significantly enhanced from a student-learning perspective. This could be done by combining the economy and face-to-face interaction available via Internet-based, video teleconferencing systems with the organization and multimedia aspects of online platform programs. The integration of these two educational delivery systems in support of a given class combines the multimedia instructional approach with the advantage of the student accessing the class from a home, office, or vacation location at a time of his/her choosing. It also allows face-to-face interaction and discussion in scheduled synchronous modes to better replicate the reality and human relations aspects of the classroom. In addition, for those students who feel they need some time on site with the instructor, a hybrid class, wherein some of the class sessions are held in the classroom and some of the class sessions are split between online sessions and Internet video teleconference systems, provides the best and the greatest flexibility of both the online and the onsite worlds.

\section{HYPERMEDIA APPLICATIONS AND ONLINE PROGRAMS/INTERNET VIDEO SYSTEM INTEGRATION}

The rationale for using online programs and Internet video teleconferencing systems in accelerated programs is that by their very structure, they are technologically capable of supporting multimedia instructional approaches. Learning theories, especially that of Gardner's Multiple Intelligences (Gardner, 1993) advocate multimedia instructional approaches to enhance learning. Multimedia is the combination of the various types of media such as video, sound, text, graphics, color, etc to better communicate and display the characteristics of a thought, function, principle, or concept. Multimedia information can be further enhanced by using hyper-linking techniques that allow the instructor or student to access any number of multimedia resources instantly by clicking on a word or phrase. When multimedia information is accessed by using hyper-linking techniques, the resulting integration is called hypermedia. Online classes, in particular, are designed with hypermedia applications which 
allow information from anywhere on the Internet or the instructor's or student's computer to be accessed instantaneously in a non-linear manner which greatly enhances the flexibility of when and how the information is accessed. They also enhance the quality of the accessed information, the speed with which it is accessed since the information is selected, and the website/file location is identified in advance.

\section{LEARNING THEORIES, ONLINE PROGRAMS/INTERNET VIDEO SYSTEM, AND HYPERMEDIA INTEGRATION}

\section{THE MULTIPLE INTELLIGENCES THEORY}

Gardner (1993) postulated that the learner learns via a variety of intelligences, not just the verbal and mathematical as so long believed. An instructor using the traditional instructional techniques of lecturing supported by textbooks in which the subject matter being taught was explained could readily communicate with the verbal and mathematical intelligence learner. Chalk or similar boards as well as transparencies placed on a lighted projection glass plate also were adequate for displaying written and charted information for the verbal and mathematical learner. However, when other intelligences postulated by Gardner, such as spatial (reasoning related to space, navigation, location), musical (reasoning related to music), bodily-kinesthetic (reasoning related to bodily movement), interpersonal (reasoning related to relationships to others) and intrapersonal (reasoning related to personal, internal aspects), are considered, traditional classroom instructional techniques fall short.

A hypermedia instructional approach, such as that inherently designed for online programs or incorporated in a part-online and part-onsite program called a hybrid, is arguably a feasible and economical approach to addressing the multiple intelligences in instruction. Although hypermedia and Internet video conferencing techniques can certainly be used, and should be used, in an on-ground classroom setting, it is often the case that every student in the class lacks a computer with Internet access at her/his desk. Moving to a hybrid approach allows each student to use a home or office computer for access and thereby partake in the advantages that hypermedia and Internet video conferencing offer. With such computer access, given that the online/hybrid curriculum and/or the video conference agenda have been designed for a hypermedia lesson plan, all of the multiple intelligences learning styles can be addressed for the maximum learning enhancement of all students-including those with disabilities. Research supports using computers and hypermedia techniques. In a five-year study, researchers at SRI International (2000) found that students under multimedia instructional approaches outperformed comparison non-technology using students in communication skills, teamwork, and problem solving.

\section{CONSTRUCTIVIST LEARNING THEORY}

Constructivist teaching is based on research showing that learning is deeper and more meaningful when students are actively involved in the learning process rather than passively receiving information (Armstrong \& Chen, 2002). The constructivist view, which appears to support the above finding by Armstrong and Chen (2002), as represented by John Dewey and Lev Vygotsky, holds that learners generate their own knowledge through experience-based activities rather than lectures given by teachers (Roblyer, 2003). Roblyer (2003) also found that multimedia development and web-based learning provided ideal conditions for supporting constructivist curriculum goals such as providing vivid visual support that helps students develop better mental models that enhance problem solving. These visual media assist in making up for student deficiencies in such learning prerequisite areas as reading and they also help to involve and motivate students by utilizing graphics and other media that students find interesting and attractive.

\section{CONSTRUCTIVISM AND MULTIMEDIA/HYPERMEDIA}

Distinct advantages are realized when using a multimedia rich environment; the student can develop pattern recognition skills from videos and access information in all media modes in a random manner which takes the learner out of the traditional sequential environment and into one in which he/she can explore the domain from multiple perspectives (Cognition and Technology Group, 1990). 
Research (Kozma, 1991) suggests that a number of concepts can be explored using hypermedia's cognitive flexibility capability. For example, a learner may be interested in researching information about land navigation. Searching in this area could turn up information about magnetic principles, topography, compass usages, terrain orientation, coordinate systems, and celestial navigation. The student researcher could follow one or all of these links, all of which would provide further links. There might also be an opportunity for the researcher to view a video regarding participants actively engaged in the sport of orienteering or he/she could participate in simulations using triangulation to determine a given location. This Internet hypermedia experience would most likely stimulate the student researcher to form mental models or associations between various ideas followed by the construction of the meaning between these relationships.

\section{CONSTRUCTIVISM AND THE MULTIPLE INTELLIGENCES}

Considering the definitions and characteristics of the theories of multiple intelligences and constructivism as outlined above, it could be postulated that the two theories complement one another in that an individual could use a combination of her/his multiple intelligences engaging multimedia/hypermedia tools to construct an individual view of the world. Where learning is concerned, research, as referenced in above pages, would seem to indicate that multimedia/hypermedia techniques using technology lend themselves more effectively in assisting the learner in constructing her/his knowledge of the world than the traditional lecture approach supported by textbooks. This is accomplished by providing more effective visualization and simulation of the real world.

\section{HYBRID CLASSES AND HYPERMEDIA/MULTIMEDIA}

Positive and enthusiastic feedback received by the authors from online students combined with the advocacy by learning theorists for using such applications, are strong reasons, in the view of the authors, to adapt and utilize hypermedia technology applications using a hybrid of onsite and online curricula/video teleconferencing techniques to do so. Considering that hybrid classes with an online/Internet video component, by definition and prerequisite, require the instructor and all the students to have modern computers with multimedia applications and Internet connections for the online portion of the class, there is no excuse as with many on-ground only classes, that access to technology equipment and the Internet are not readily available and thereby hypermedia instructional techniques are not feasible. All the tools and technology are there for the hybrid online-hybridInternet video using instructor and student. It appears that the hybrid class approach addresses the usual obstacles of too little technology, too little training and too little time that is required to utilize the proven instructional advantages of hypermedia and multimedia instructional techniques.

Given that most students take online/hybrid classes because it allows them more flexibility as to the place and time of instruction, a balance would have to be maintained between aspects of the class that allow students to access and do the assignments at a time of their choosing with aspects of the course (such as synchronous chats and Internet video conferencing) where they would need to participate at a specific time specified by the instructor. Though some flexibility in time would have to sacrificed, the face-to-face interaction with the instructor and students in the onsite sessions or the video conferencing sessions-especially when reviewing and discussing complex subjects or multimedia projects--would more than compensate by providing instant feedback to student questions and requests for clarification.

\section{A HYBRID EXPERIENCE USING HYPERMEDIA}

National University (NU) is currently piloting the integration of the Blackboard online instructional platform/system and the iLinc Internet based video teleconferencing system with an onsite classroom approach (hybrid) to test the belief that combining these instructional delivery systems will significantly enhance learning in NU's one month per course-accelerated program. One of the authors recently taught a hybrid technology class of 12 students - all adult teachers seeking a masters degree at an offsite location in the mountains 24 miles from campus. Of the nine class sessions, three were conducted using a combination of online and video conferencing and six were conducted onsite in a classroom at a middle school. Multimedia/hypermedia instructional techniques were used in all modes--onsite, online, and Internet video teleconference. 
The first class was conducted onsite and the concepts of multimedia and hypermedia instruction were demonstrated in the initial class by using a hyperlinked Power Point presentation to review the course syllabus and to lead a hands-on instructional phase to allow the students to use the classroom computers to develop an basic and relatively simplified Power Point presentation of their own. Next, the students used the classroom computers with headsets to access the Internet and $\log$ on to an iLinc Video Teleconference demonstration. The students were shown, and they practiced, how to use the iLinc menu to "raise their hands" to gain the attention of the instructor facilitator to give them access to speak and how to use the text tool to send text messages to provide pertinent information while the video and audio portion of the session was active. They were advised to obtain a headset with a microphone so that they could talk as well as listen and exchange text messages.

The second-class session was conducted via iLinc. Students were arranged in groups of four and allowed to choose a location (their school, the middle school classroom, or their home) from which they would access and participate in the iLinc class. The instructor conducted the session from his home. The students were grouped in order to promote collaboration in the initial Internet iLinc session and to reduce the fear of using a new technology tool on which they had received instruction and a demonstration the night before. The instructor believed that the group, working together, would be better motivated and also more capable of problem solving any technical or menu problems posed by accessing the iLinc session. All groups were successful in accessing the session and in using both the audio and text communication portion of the class session. Since the students had not yet obtained a webcam, they could not participate in two-way live video; however, they could see the instructor live via his webcam.

The third class session was conducted in the middle school classroom and the first item on the agenda was a critique of the iLinc session. Students were very pleased that they, as group problem solvers, had figured out the technical challenge of accessing the iLinc session as well as their ability to negotiate the iLinc menu to communicate during the session. They were highly excited about being able to participate in the class from a variety of locations (one group came to the middle school classroom, one group participated from their primary school site, and one group participated from a student's home). They pointed out how great this Internet connected approach would be in subsequent winter classes when the National University professor may not make it to class (as happened last year) because of mountain road closures due to snow or ice. Often students were snowed in as well and the iLinc hookup would allow them to attend class from home via the Internet. After the iLinc critique, the students were shown how to use hyperlink techniques to access multimedia instructional material on the Internet as well as to various files on their computers.

In the fourth class session, students participated as individuals from locations of their choice. The session was conducted via the Internet using a combination of online Internet webquest assignments as well as an iLinc video teleconferencing session in which the instructor presented a Power Point tutorial on designing and conducting webquests; two students presented multimedia Power Point presentations on assigned chapters in the course textbook after which they answered questions. A webquest (Dodge, 2003) is an inquiry-oriented activity in which some or all of the information that learners interact with comes from resources on the internet, optionally supplemented with videoconferencing. The session was recorded for two students who had to attend their schools' back-to-school nights and could not participate. They were able to sign on to the iLinc website the next day and view the iLinc session including all of the Power Point presentations and accompanying question and discussion period.

In the fifth class session, the second iLinc session was critiqued by the class who reported no significant access or menu usage problems. The two students who did the Power Point presentations stated the iLinc menu was easy to use, the students who viewed their presentation affirmed that it was easy to follow, and the two students who were absent and reviewed the recorded session said they felt like they were actually watching it live and very much appreciated the session being recorded for them.

The remaining sixth, seventh, and eighth classes were conducted onsite where students studied and practiced multimedia presentations using hypermedia instructional techniques to develop webquests for their classrooms and back-to-school night presentations for their various schools. The last class used online instructional techniques to discuss various aspects of using Internet online and video conferencing and to complete an exam on using technology, multimedia, and hypermedia technology applications to enhance both instruction and learning. 
The instructor's assessment based on student reaction and comments during the course is as follows:

- $\quad$ These adult students, who have a fulltime teaching job during the day and family demands during the evening, commented that attending a four and a half hour class two nights a week, combined with the homework in-between classes, really placed them under a time crunch resulting in a great deal of pressure. The advantage of the hybrid class in being able to attend the several class sessions from their own classroom or home was a godsend and saved them a great deal of time while reducing a significant amount of pressure.

- $\quad$ The students, as a result of using technology in a meaningful and useful way (i.e. using the Internet and their computers to communicate with their classmates and the instructor to receive class instruction at a place of their choosing) excited them and at the same time gave them confidence in their abilities to use leading-edge technology successfully.

- Their excitement and confidence generated from using the online instruction and the Internet video conferencing systems fed over into their study and use of multimedia and hypermedia instructional techniques. Three of the class members put together a hypermedia Power Point presentation for their backto-school night events and commented on how easy it was and how much their principals and peers were impressed.

- $\quad$ The usual negative questions and skepticism of students in normal onsite class members about the value and utility of technology and related instructional techniques vanished after the second-class session when they used the Internet video teleconferencing system to receive the class instruction and never resurfaced.

- The majority of the class, based on a first night objective assessment of their coming-in existing technology skills, did not know how to do a Power Point presentation, develop a basic Excel spreadsheet, or attach a file to an e-mail. Because they were so turned on about technology and so highly motivated by actually using technology so effectively in the online and video conferencing portions of the class, they became proficient and overcame all of the above noted weaknesses midway through the class.

\section{CONCLUSIONS}

When a university puts in place an academic program at an accelerated pace primarily for working adults, every possible proven instructional technique that enhances learning while reducing the time required to learn, should be used. At the same time, since working adults, many with families, have a finite amount of time to earn a living, spend time with their family, and take classes toward a degree, every possible instructional delivery mode that can save the adult learner time in both transportation and knowledge acquisition should be used. Multimedia and hypermedia instructional techniques have been proven by a large body of research, some of which has been referenced in this paper, to enhance and speed learning by addressing all of the multiple intelligences of the learner.

Online and Internet based programs, which must use technology and computers for delivery of the instruction, inherently utilize multimedia and hypermedia techniques as a matter of course. It can be deduced that online instructional programs, given that the online design, development, and implementation of a given course are sound and utilize their technology potential, must be superior in their instructional potential than an onsite program. In an onsite course, computers may not be available and the instructor may not have the technology tools that allow each of the multiple intelligences to be addressed.

Hybrid courses, in which at least some of the sessions are conducted online and therefore must use hypermedia and multimedia instructional techniques that thereby potentially address all of the learner's multiple intelligences, can likewise, as noted above, be expected to be somewhat more effective than an onsite course. In the onsite course, the instructor may be limited to the lecture mode with the typical chalk or dry erase board for information presentation. Since hybrid courses are just now beginning to be used, as is the case at National University, there has been insufficient time to gather enough empirical data to prove the case. The authors, however, based on their experience in the last six months with hybrid courses, predict the case will be made. Perhaps the case can be presented at the next conference. 


\section{AUTHOR INFORMATION}

Dr. E. George Beckwith is an Associate Professor of Educational Technology at National University, San Diego and recently gave presentations at Cambridge University (Gaming Education rather than Violence) and Tulane University (The Gap Between Traditional Professors/Teachers and Digital Age Students). He is responsible for teaching Educational Technology Courses both onsite and has designed, developed and implemented educational technology courses for onsite and online classes. He serves on the NU President's Commission for Online Education, is a member of the Faculty Senate and the Graduate Council. He was previously a Director of Technology at the Inglewood and Los Angeles Unified School Districts and instructed teachers on using multimedia technology in the classroom. He also served as a Computer-Communications Officer in the United States Air Force and retired as a Colonel. His Bachelor's Degree in Experimental Psychology is from the University of Georgia in Athens, his Masters Degree in Educational Psychology is from Wayne State University in Detroit, and his Doctorate in Educational Leadership is from United States International University in San Diego. Dr Beckwith was awarded the 2008 Faculty Service Award from National University.

Dr. Daniel T. Cunniff is an Associate Professor and the Lead Faculty for Educational Administration at National University's Fresno, California, campus. He received his B.S. and M.A. from Northern Illinois University and his $\mathrm{Ph} . D$. from Walden University. He has taught at Portland State University and California State University in San Marcos. He was the recipient of a 2006 President's Professoriate Award for outstanding contributions "above and beyond" his regular work assignments presented by the Chancellor of National University. As an international business analyst, he was an independent consultant to major Fortune 500 companies, including organizations in Indonesia and Canada. He was an Assistant Superintendent for Secondary Education in Fairbanks, Alaska; Educational Advisor of Education Television in American Samoa; Principal and Acting Superintendent in San Diego County; and an Elementary Principal and teacher in the Chicago suburbs. Dr. Cunniff is also the Coordinator of the International Academic Professor Exchange Program for National University, which is based in La Jolla, California. This position has enabled him to present papers on various educational and business topics at conferences in Panama City, Panama; Belfast, Northern Ireland; Toronto, Canada; Orlando, Florida, and San Diego, California. Dr. Cunniff received the 2008 Phi Delta Kappa Research Award from the Fresno, California chapter.

\section{REFERENCES}

1. Armstrong, S, \& Chen, (2002). Edutopia, success stories for learning in the digital age. San Francisco: Jossey-Bass Books.

2. Cognition \& Technology Group (1990). Anchored instruction and its relationship to situated cognition. Educational Researcher, 19(5), 2-10.

3. Dodge, B. (2003). The webquest page. Retrieved October 2, 2005 from http://webquest.sdsu.edu.

4. Gardner, H. (1993). Multiple intelligences: the theory in practice. New York, NY: Harper Collins Publishers.

5. Kozma, R. (1991). Learning with media. Review of Educational Research, 61(2), 179-211.

6. Roblyer, M. (2003) Integrating educational technology into teaching. Upper Saddle River, NJ: Pearson Education Inc.

7. SRI International (2000). Evaluation of Challenge 2000 Multimedia Project. Center for Technology in Learning, Retrieved October 2, 2005 from: http://pblmm.k12.ca.us/sri/SRIEvaluation.htm 